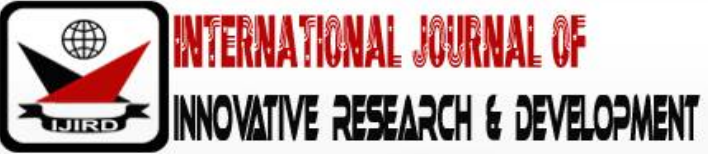

ISSN 2278 - 0211 (Online)

\section{Risk Factors Associated with the Occurrence of Porcine Cysticercosis in Kiambu, Kenya}

Dr. Mwangi N. Samuel
Postgraduate Student, Department of Animal Sciences, Basic Degree in Veterinary Medicine,
Specializing Animal Production Systems with Emphasis on Nutrition, Kenyatta University, Kenya
Dr. Purity N. Nguhiu
Lecturer, Department of Animal Science, Expertise in Area of Animal Health and Zoonosis,
Kenyatta University, Kenya
Lucy W. Kabuage
Professor, Department of Animal Science, Expertise in Animal Production with Emphasis on Feeding
of Non-Ruminant Animals, Kenyatta University, Kenya

\begin{abstract}
:
Porcine cysticercosis is parasitic diseases of pigs caused by the larval stages of Taenia solium (pork tapeworm) and appears as cysts in the muscles, organs and central nervous system. Pigs acquire the infection by ingestion of contaminated feed and water with taenia eggs shed in faeces by infected humans. This condition leads to economic loss as infected carcasses are condemned at slaughter. Humans acquire the infection by consumption of infected and undercooked pig meat where the adult worm resides in the small intestines of infected humans (Taeniasis) and the larval stages are found in the muscles, brain and other tissues in humans with neurocysticercosis being of major public health concern. A study to evaluate the risk factors in pig production management systems that would contribute to the occurrence of porcine cysticercosis was carried out in four study sites in 2016. A total of 81 pig farms were visited, structured questionnaires were administered to the pig farmers to collect data on socio- demographic, water and sanitation, pig husbandry practices and awareness on porcine cysticercosis from one member of each household. Observations were made on the management systems especially feeding and housing of the pigs. In an earlier study, the prevalence of porcine cysticercosis had been estimated by lingual examination. Logic regression analysis was done to determine the relationships between porcine cysticercosis and management practices level. The pig stock sizes were ranging from 1 pig to 78 pigs and with an average of 11.12. Majority (97.5\%) of pig farmers in the study area practiced zero grazing system. In order of preference, the farmers reported to feed their pigs on manufactured commercial feeds, home mixed feeds, swill from hotel and garbage, household left over, and fodder from garden. The main source of water for watering livestock was tapped water within the compound which was reported by $71.6 \%$ of the respondents. Other sources were wells and borehole reported by $27.2 \%$ and $1.2 \%$ of the respondents respectively. On animal health practices, $88.9 \%$ of the pig keepers de-wormed their pigs while $97.5 \%$ sought veterinary services. There were $69.1 \%$ of the respondents who reported that they usually buy replacement pigs. All the respondents kept pigs for commercial purposes. Porcine cysticercosis was significantly associated with sources of household income $(p=0.033$, the practices of feeding pig on home mixed feeds $(\mathrm{p}=0.006)$, neighbors' leftovers $(\mathrm{p}=0.001)$, and swill $(\mathrm{P}=0.001)$ and also frequency of de-worming pigs $(\mathrm{p}=0.027)$. The main risk factor for porcine cysticercosis was the feeding of uncooked swill (odd ratio=7.97). This study is significant in that it has documented for the first-time management risk factor associated with cysticercosis in the study area. The results of this study may be used to advice on improved pig husbandry practices and to design strategies for the control of Taenia solium taeniasis and cysticercosis in the study area.
\end{abstract}

Keywords: Risk, Cysticercosis, swill, Taeniasis

\section{Introduction}

Agriculture is the main stay of Kenyan economy and its importance is highlighted by its enormous contribution to the countries' industrial product and exports (FAO, 2012). Although pig sector contribution to Kenyan economy is small, the sector possesses a huge potential which can be exploited (Behnke and Muthami, 2011). The main hindrances to the growth of pig sector in Kenya include poor infrastructure, unreliable feed availability, poor sanitation, in adequate veterinary services as well as poor husbandry practices (FAO, 2012).

There are three pig production systems in Kenya; Free range traditional systems, small scale intensive system and large scale intensive commercial systems. Free range traditional systems are also known as extensive system because pigs are allowed to roam freely and feed on a variety of feeds including crop residue, kitchen left over, by products of crops as well as grazing on grass (Eshitera et al., 2012). Free range traditional system is mostly found in Nyanza, western Kenya and slums in urban areas (FAO, 2012). It is characterized by few animals kept, poor feeding system, disease challenges, few 
breeding boars, poor profit, lack of skills and money to build houses as well as seasonal tethering of pigs during planting, growing and crop harvesting (Mutua et al., 2011). The main decision makers on the husbandry practices and methods of pig keeping are either women or men and women together while the day to day care of pigs is done by women (Nantima et al., 2015). Small scale intensive system is mainly found in Central Kenya, the former Eastern Province, and the Northern and Central parts of the former Rift valley Province (Behnke and Muthami, 2011). Number of pigs kept range from fewer than 10 up to100 (Wabacha et al., 2004). Most farmers in this system mix their own feed while in some areas farmers have formed cooperative societies with feed mills e.g. Meru Central cooperative society (FAO, 2012). Large scale intensive commercial pig keeping systems is found in the same regions as small-scale intensive system. Large number of pigs kept in this system at times more than 5000. These farms belong to Farmers' Choice and pigs are raised and slaughtered by Farmer's Choice (FAO, 2012).

Poor housing is one of the major constraints to pig production in third world countries (Ironkwe and Amefule, 2008; Wabacha et al., 2004). In developing countries, pig houses are characterized by poor wind protection, poorly constructed floor which are usually wet, improperly constructed waste disposal system and normally lead to high worm infestations (Lekule and Kyvsagaard, 2003). In free range or extensive system, houses are constructed using locally available material and usually, pigs are housed at night and during crop growing period (Mutua et al., 2012).

According to a study conducted on 164 pig farmers in Busia District, Western Kenya, the most frequent feedstuffs used by small holder farmers in western Kenya are ground maize, ground fish and kitchen leftovers (Mutua et al., 2012). Feed and feeding costs make 75 -80\% of total pig rearing cost (Smith, 2008). This is because the bulk of pig feeds (more than 55\%) are composed of grains which also form part of human food basket (Smith, 2008). Pig digestive system, compared to other domestic animals, has the highest similarity to human (Haynes, 2001). High cost of feed was found to be one of the major constraints to pig farming in Kikuyu region in Kenya (Kagira et al., 2009; Wabacha et al., 2004) .

Majority of small holder farmers in Kenya are on the lookout for cheaper ways to feed their pigs (FAO, 2012). It has been observed that in some third world countries farmers avoid commercial feeds made from grains and grain by products which are expensive due to competition with human (Petrus et al., 2011). Swill (house hold leftovers collected from dam sites) and kitchen leftovers have been documented as a common alternative in many areas of third world countries (Ajala et al., 2007; Carter et al., 2013; Kamuribo et al., 2011; Kagira et al., 2010; Ocampo et al., 2005; Phengsavanh et al., 2010). Swill has been associated with spread of diseases especially Taenia solium cysticercosis between human and pig (Haynes, 2001). In India, cooking of swill has been done and successfully reduced spread of diseases (Ajala et al., 2007; Phengsavanh et al., 2010). Use of brewers' grain has been documented in Nigeria and Namibia (Haynes, 2001). Pig feeding systems in central Kenya region has not been characterized in terms of feed stuffs used, quality of the feed stuffs and feeding of the various groups of pigs.

Water an important component in pig nutrition and is required in large amounts for physiological body functions. At birth, water forms $82 \%$ of a pig by weight and by the time a pig is 104 kilograms, $51 \%$ of the body is water (Shields et al., 1983). Water has a number of physiological functions in pig which includes; regulation of body temperature, forms part of body tissue, takes part in tissue metabolism, maintains mineral homeostasis as well as helps in excretion of metabolic end products especially urea (Brooks et al., 1989). Although pig gets most of their water requirement by drinking, part of water is ingested together with feeds. Requirement of water for pig vary with age and physiological status as shown in the table below (Froese and Small, 2001). The lactating sows have the highest daily water requirement and consumption while the weaned pigs have the lowest requirement.

Worldwide, sources of water for pig use include public tap outside the compound, dams, rivers, wells and boreholes (Peden et al., 2003). The origin of most of Kenya's water is its five water towers namely; Aberdare range, Mount Elgon, Mount Kenya and the Cherengani Hills (NEMA, 2010). Drinking water for pig should be clean to avoid infections (Brooks et al., 1989). Thika and Murang'a Counties get water from Aberd are range water tower. According to 2009 Census, the former Central Province with 91,977 pigs had the highest number of pigs followed closely by the former Western Province with 84,838 pigs (KNBS, 2009). While most of pigs (more than 90\%) in western province were kept under traditional backyard system, only about $20 \%$ of pigs in central province are kept under this system. Pigs in Kenya are mainly kept in small scale extensive system, small scale intensive system and commercial system (Behnke and Muthami, 2011). Extensive system, normally referred to as free range pig rearing system, is found mostly in western parts of Kenya and in slums of the major towns while small scale intensive system and commercial system are found in central Kenya and parts of Rift valley (FAO, 2012). There is limited information on herd sizes in Kenya, however a study conducted in western Kenya indicated that the number of pre-weaned, growing and adult pig/ per farm was $5.0( \pm 3.4), 1.8$ $( \pm 1.2)$ and $1.5( \pm 0.9)$ respectively (Mutua et al., 2011).

Health issues in pig that requires to be solved include treatment of various diseases, vaccination against certain diseases and parasite control (FAO, 2012). Internal and external parasite infestations have been reported most frequently by farmers in some studies (Ajala et al., 2007; Kagira et al., 2003; Kamuribo et al., 2011; Lekule and Kyvsagaard 2003 and Mutua et al., 2012). Worm control has been hindered by misuse of anthelmintic which in some cases has resulted to resistance (Steinfeld, 2003).

Reported causes of early piglet mortality include piglet being squashed by their mother, worm infestation, mange, diarrhoea, lice infestation and nutritional deficiencies (Ajala et al., 2007; Kagira et al., 2003; Mutua et al., 2012; Mutua et al., 2011). Cysticercosis has been reported as a disease concern for pig and a major public health concern in most rural pig husbandry (Kagira et al., 2003; Mutua et al., 2011; Mutua et al., 2012; Veary and Manoto, 2008).

Remarkable efforts to control diseases have been reported in some areas. More than $60 \%$ of respondents in a study conducted in Kaduna, Nigeria said they vaccinate their pigs against common diseases (Ajala et al., 2007). In ability to describe diseases has also been observed in other studies where respondents had reported that they did not experience 
any disease problem (Mutua et al., 2010; Petrus et al., 2011).Porcine cysticercosis complex is an emerging public health and animal production concern across the globe with cases emerging in non-endemic areas due to international immigration and the changing pig production patterns due to an increase in the production costs (Zoli et al., 2003). The global prevalence is estimated at about 8\% (FAO, 2012). Both human and pig infections have been reported in South Africa, Zimbabwe, Gambia, Togo, Rwanda, Burundi, Malawi, Swaziland, Madagascar and Zaire (Zoli et al., 2003). In Tanzania, cases of porcine cysticercosis were first reported in Mbulu District (Boa et al., 1995) where the prevalence was estimated at $17.4 \%$. In Uganda, $9.4 \%$ of pigs surveyed were found positive by lingual palpation for cysticercosis with most cases coming from the rural areas (Kisakye and Masaba, 2002). However, most of the endemic areas especially in sub Saharan Africa lack proper documentation of this particular disease while the risk factors to its transmission are eminent. Thika sub County, being a major producer of pork in the country and the region, lacked any documentation of porcine cysticercosis and therefore, this study sought to provide current information on pig management practices in Thika sub County. Management practices that may contribute to cysticercosis infection were also to be identified as well as the risk factors for the occurrence of porcine cysticercosis in a region.

\section{Materials and Methods}

\subsection{Study Location}

This study was carried out in Thika Sub-County in Kiambu County, Kenya and Kimorori ward of the neighboring Muranga South Sub-County of Muranga County. Thika sub county is one of 12 sub-counties in Kiambu County lies between latitude $1.45^{\circ} \mathrm{S}-3.53^{\circ} \mathrm{S}$ and longitude $36.35^{\circ} \mathrm{N}-37.25^{\circ} \mathrm{N}$ (Kiambu County council, 2015). Thika town serves as the head quarter to the sub-county and is about $40 \mathrm{Km}$ from Nairobi city (Kiambu, 2013).

\subsection{Study Design and Sampling}

A cross sectional survey was carried out in Thika sub county, Kiambu County Kenya and Kimorori ward in Murang'a County. A semi structured questionnaire was administered to randomly selected farmers to get information on various management pig practices. All the pig farmers in Kimorori ward in Muranga County and Thika Sub County in Kiambu County at the start of the study were included in sampling frame. At the beginning of the study, 178 farmers were identified and their contacts recorded. Each ward was sampled separately where raffles of all farmers were prepared for each ward and a blind folded person aided in picking the sample. The 90 farmers from all the four wards were picked and formed the study sample.

A semi-structured questionnaire was administered to all the 90 farmers to get information concerning the bio data of the farmers, their background characteristics as well as their various management practices. An initial study had been conducted on the sampled farmers to determine prevalence of cysticercosis in the area where pigs in those households were randomly selected and examined once by lingual palpation for presence of cysts which appears as a nodule below the tongue (Nguhiu et al., 2018). All households that had a positive case were recorded as positive while those households that had no positive case were recorded as negative for cysticercosis.

\subsection{Data Analysis}

The data collected was entered into computer Version on excel where cleaning and errors were corrected. SAS 2010 was used to analyze the background characteristics of pig farmers. Proportions including means and percentages as well as association of risk factors to occurrence of disease which include odd ratios, relative risk and attributable risk were calculated. The strength of relationship between management practices and Cysticercosis was tested and management practices that may have high risk of infection established.

\section{Results}

\subsection{Socio- Demographic Data}

The distribution of the farmers according to ward was as shown in the Table 1 where $51.9 \%$ of the farmers were from Kamenu, 22.2\% from Gatuanyaga, 6.2\% from Township, and 19.9\% from Kimoror Wards, respectively. The respondents comprised of females (55.6\%) and males (44.4\%) with age range between 20 and 69 years and all were Christians. Among the households visited, $89 \%$ kept other livestock alongside pigs. Majority of the respondents had formal education where only $1.2 \%$ lacked any formal education (Table 1 ).

On the main source of household income, $37.0 \%$ of the respondents practiced animal husbandry, $24.7 \%$ were in salaried employment, $17.3 \%$ were casual labourers, $13.6 \%$ were in various businesses, $6.2 \%$ were crop farmers while a minority of $1.2 \%$ respondents relied on assistance/ hand outs. Sources of water for domestic were reported by a majority (77.8\%) of the respondents that they relied on tapped water inside the compound and the rest got water from wells (18.5\%), public tap (2.5\%) and boreholes $(1.2 \%)$. All households reported to own latrines with $75.3 \%$ respondent reporting that they had a pit latrine while $24.7 \%$ reported that they had a flush toilet. All the respondents reported that they usually wash their hands after using the latrine.

\subsection{Management Practices}

The total number of pigs owned by all the households visited was 910. The stock size in the house holds visited was ranging from 1 pig to 78 pigs with an average of 11.12 and a standard deviation of the mean of 14.12 . A total of $58(71.6 \%)$ households had less than 10 pigs while $13(16.1 \%)$ had 11 to 20 pigs and further 10 (12.3\%) had 21 to 78 pigs. 
On the ranging systems, a total of $79(97.5 \%)$ practiced zero grazing system while $2(2.5 \%)$ kept their pigs under restricted grazing system. A small number (2.5\%) respondent reported that they allowed their pigs to roam in a yard with one of them allowing them to roam sometime and the other one allowing them to roam always. No respondent reported that they allowed their pigs to roam outside the compound.

On the pig feeding, various feed sources were reported. In order of importance the feeds reported included manufactured feeds, home mixed feeds, swill from garbage, house hold leftovers or waste, neighbors' leftovers and fodder from garden. Majority of the farmers offered the swill and food left-overs as collected hence uncooked while small minority would cook the swill before feeding the pigs. The sources of water for pig was reported to be tapped water inside the compound, well and borehole which were used by $71.6 \%, 27.2 \%$ and $1.2 \%$ of the respondents respectively.

On replacement stocks, $69.1 \%$ of the respondents reported that they usually bought replacement pigs while $30.9 \%$ raised their own replacement pigs. Majority (60.5\%) of the respondents kept pigs as a commercial enterprise while the rest reported they keep them for security purpose in case of emergence family needs.

Various health management practices such as de-worming and access to veterinary were reported. Majority of the respondents (88.9\%) reported that they de-wormed their pigs while11.1\% reported that they did not. The frequency of de-worming was varied with $51.9 \%$ of the respondents reporting that they de-wormed their pigs (every three months, $27.2 \%$ every six months and $9.9 \%$ once in a year (Table 1 ).

Access to veterinary services was available where $97.5 \%$ of the respondents reported that their pigs were usually attended by a veterinarian while only $2.5 \%$ of the respondents reported that they did not seek veterinary services at all. Further, $51.9 \%$ of the respondents reported that they sourced veterinary services occasionally (less than once a month), another $38.3 \%$ of the respondents reported that they rarely (less than once a month) looked for veterinarian services while $7.4 \%$ of the respondents reported that they get the services often (more than twice a month). On the perception of the veterinary services, $56.8 \%$ of the respondents felt that veterinary services are useful even when the pigs are not sick while the other $42 \%$ of the respondents felt they are only useful when the animals are sick. Only $1.2 \%$ of the respondents felt they are not necessary at all.

\subsection{Risk Factors in the Management Practices}

Binary logistic regression analysis was used to test dependence of porcine cysticercosis to various factors and management practices. On the back-ground information of the respondents, Main source of household's income was found to be significantly associated with pig cysticercosis with $p=0.033$. In this case, respondents who reported that their main source of income was crop farming were found to be more likely to have an infected pig than the rest of the respondents which could have been associated by association of crop farming with poverty. The results were as shown in Table 1.

\begin{tabular}{|c|c|c|c|c|}
\hline Variable & Score & df & p & Remarks \\
\hline Ward of residence & 2.328 & 3 & 0.507 & Not significant \\
\hline Gender of respondents & 1.290 & 1 & 0.256 & Not significant \\
\hline marital of respondents & 1.019 & 2 & 0.601 & Not significant \\
\hline Level of education of respondents & 2.910 & 6 & 0.820 & Not significant \\
\hline Main source of household's income & 12.150 & 5 & $0.033^{*}$ & Significant \\
\hline Source of water for domestic use & 1.523 & 3 & 0.677 & Not significant \\
\hline Latrine type & 0.063 & 1 & 0.802 & Not significant \\
\hline personal de-worming & 0.871 & 1 & 0.351 & Not significant \\
\hline
\end{tabular}

Table 1: Binary Logistic Regression Analysis for Association of Background Information of the Respondents to Porcine Cysticercosis

[Risk Factors with $(*)$ in the Table Were Found to Be Significantly Associated with the Occurrence of Pig Cysticercosis]

Binary logistic analysis was also done to test the dependence of pig cysticercosis to various management practices where significant association was found in the practices of feeding on home mixed feeds $(p=0.006)$, feeding on neighbour's leftovers $(p=0.001)$, feeding on swill $(P=0.001)$ and frequency of de-worming pigs $(p=0.027)$. The practices of feeding pigs on home mixed feeds, neighbour's leftovers and swill were found to increase risk of porcine cysticercosis infection while de-worming pigs every three months reduced the risk of infection. Results were as shown in Table 2.

\begin{tabular}{|c|c|c|c|c|}
\hline Variable & Score & df & $\mathbf{p}$ & Remarks \\
\hline Pig ranging system & 0.135 & 1 & 0.713 & Not significant \\
\hline Feeding on manufactured feeds & 2.249 & 4 & 0.690 & Not significant \\
\hline Feeding on home mixed feeds & 14.332 & 4 & $0.006^{*}$ & Significant \\
\hline Feeding on fodder & 0.237 & 2 & 0.888 & Not significant \\
\hline Feeding on house hold leftovers & 7.643 & 3 & 0.054 & Not significant \\
\hline Feeding on neighbour's leftovers & 16.561 & 3 & $0.001 *$ & Significant \\
\hline Feeding on swill & 17.637 & 4 & $0.001^{*}$ & Significant \\
\hline Swill cooking & 0.892 & 2 & 0.640 & Not significant \\
\hline Source of livestock's water & 0.489 & 2 & 0.783 & Not significant \\
\hline De-worming of pigs & 0.426 & 1 & 0.514 & Not significant \\
\hline
\end{tabular}




\begin{tabular}{|c|c|c|c|c|}
\hline Variable & Score & df & $\mathbf{p}$ & Remarks \\
\hline Frequency of de-worming pigs & 9.146 & 3 & $0.027 *$ & Significant \\
\hline Access to veterinary services & 0.135 & 1 & 0.713 & Not significant \\
\hline Frequency of veterinary services & 1.328 & 3 & 0.722 & Not significant \\
\hline perception on veterinary services & 0.743 & 2 & 0.690 & Not significant \\
\hline Purchase replacements & 2.379 & 1 & 0.123 & Not significant \\
\hline Source of replacements & 3.186 & 3 & 0.364 & Not significant \\
\hline Reason for keeping pigs & 3.656 & 1 & 0.056 & Not significant \\
\hline Worm sign awareness & 1.290 & 1 & 0.256 & Not significant \\
\hline Pig infection awareness & 0.022 & 1 & 0.881 & Not significant \\
\hline
\end{tabular}

Table 2: Binary Logistic Regression Analysis for Association of Pig Management

Practices to Porcine Cysticercosis

[Risk Factors with $(*)$ in the Table Were Found to Be Significantly Associated with the Occurrence of Pig Cysticercosis]

From the results of computation of odd ratio, relative risk and attributable risk of exposure to various management practices, feeding pig on swill feeding $(\mathrm{OR}=6.1, \mathrm{RR}=5.25, \mathrm{AR}=13.49)$, house hold left over $(\mathrm{OR}=3.79, \mathrm{RR}=3.53$, $\mathrm{AR}=6.67$ ), neighbour left over ( $\mathrm{OR}=4.5, \mathrm{RR}=4.02 \mathrm{AR}=10.24)$, and giving uncooked swill ( $\mathrm{OR}=7.97 \mathrm{RR}=6.35 \mathrm{AR}=13.33$ ) as well as failure to de-worm $(\mathrm{OR}=2.13, \mathrm{RR}=2.08, \mathrm{AR}=5.56)$ and purchase of replacement pigs ( $\mathrm{OR}=5.45, \mathrm{RR}=5.02, \mathrm{AR}=7.73$ ) were found to increase the risk of pig cysticercosis. The data is as shown in the Table 3.

\begin{tabular}{|c|c|c|c|c|}
\hline Variable & $\begin{array}{c}\text { Odd Ratio } \\
\text { (OR) }\end{array}$ & $\begin{array}{c}\text { Relative } \\
\text { Risk (RR) }\end{array}$ & $\begin{array}{c}\text { Attributable } \\
\text { Risk (AR) }\end{array}$ & Remarks \\
\hline Swill feeding & 6.1 & 5.25 & $13.49^{*}$ & Significant \\
\hline House hold left over & 3.79 & 3.53 & $6.67^{*}$ & Significant \\
\hline Feed from manufacturer & 0.34 & 0.37 & -7.88 & Not significant \\
\hline Fodder from garden & 1.28 & 1.26 & 1.41 & Not significant \\
\hline Home mixed feeds & 1.67 & 1.61 & 2.93 & Not significant \\
\hline Neighbour left over & 4.5 & 4.02 & $10.24^{*}$ & Significant \\
\hline Feeding with uncooked swill & 7.97 & 6.35 & $13.33^{*}$ & Significant \\
\hline Failure to de-worm & 2.13 & 2.08 & $5.56^{*}$ & Significant \\
\hline No veterinary services & 1.36 & 1.33 & 1.85 & Not significant \\
\hline Purchase of replacement pigs & 5.45 & 5.02 & $7.73^{*}$ & Significant \\
\hline
\end{tabular}

Table 3: Odd Ratio, Relative Risk and at Tributable Risk on the Risk Factors to Pig Cysticercosis

[Risk Factors With $(*)$ in the Table Were Found to be significantly Associated with the Occurrence of Pig Cysticercosis]

\section{Discussion}

Most of the respondents in this study were women who were usually left at home to take care of the livestock as their husbands did other jobs away from the homestead. This concurs with studies done in western Kenya which showed higher female than male respondents (Kagira et al., 2010; Mutua et al., 2012; Mutua et al., 2011; Mutua et al., 2007). In many parts of the world, labour for pig husbandry is mainly provided by women and the same was reflected in Thika. This study also concurs with various other studies by International Livestock Research Institute (ILRI) of who estimated that among about 600 million poor livestock keepers all over the world, around two-thirds of them are women (FAO, 2011; Thornton et al., 2002).

A majority of the respondents were from Kamenu ward which is peri urban area and concurs with studies done in Brazil, Mexico and Peru which found out that most of the pig farming was in peri urban areas due to proximity to the market and source of feed (Garcia et al., 2002). Majority of the respondents had taped water in the compound and had latrines. The finding that majority of the pig farmers have access to tap water which is major source of water for their pigs is different from other studies in Africa where the researchers pointed out that most of countries in sub-Saharan African lacks basic sanitation facilities such as latrines and do not have access to tap water (Sikasunge et al., 2006). Tap water is usually treated and therefore reduces transmission of cysticercosis.

Majority of farmers kept small herd sizes of less than 10 pigs, with a small minority having herd sizes of over 100 pigs. A number of the farmers said they kept few animals due to fear of African swine fever which is endemic in the area and had caused massive losses to farmers in the past. Also, most of the farmers had other sources of income and only kept a few pigs to provide extra income. The findings of this study concur with studies in western Kenya where majority of pig farmers keep smaller herd size with an average of two pigs per household and with a sole purpose of supplementing their sources of income as it was found in Kiambu county where the findings of this study indicate that pigs are kept as a source of income (Kagira et al., 2010; Mutua et al., 2012; Mutua et al., 2011; Mutua et al., 2007). 
Majority of the farmers practiced zero grazing system while only a few kept their pigs under restricted grazing system. The findings were not consistent with a study that was done in western Kenya where free-range system is common (Mutua et al., 2007). Therefore, the prevalence was found to be lower in the study area than reported in the western Kenya study. Pig confinement in the study area was reinforced by a ban on free keeping of pigs in the municipality by the former Thika municipal council as reported by the sub-county veterinary officer, which may have contributed to low transmission. In the study area, pigs were confined in structures that ranged from temporary wooden houses with earthen floor and lacking roofing, to well-constructed permanent pig houses with good well drained easy to clean floor and good roofing. Those houses in their simplicity or complexity were used to permanently confine pigs. This concurs with findings by other researchers in Kenya (Kagira et al., 2010; Mutua et al., 2012; Mutua et al., 2011; Mutua et al, 2007) who reported that locally available materials were used to construct pig houses in western Kenya.

Although most farmers preferred feeds from manufacturers, the need to cut cost on production has made them exploit other feed sources that cost less. The standard of feeding in Thika thought was much higher as compared to western Kenya where previous study by had shown that most farmers preferred locally available feed stuffs such as maize floor, dried fish and kitchen leftovers (Mutua et al., 2012).

Pig water sources were found to be mainly from piped water from taps in the home compound. The findings of this study do not concur with findings by Eshitera et al. (2010) in a research done in Homabay which found out that a majority of the respondents did not have potable water and relied on borehole and water from dams. In Homabay, domestic water treatment was reported at $40.5 \%$ unlike in Thika where majority of the respondents have access to treated water which thus is unlikely to be contaminated with T. solium eggs and hence does not encourage the transmission cycle.

Most of the farmers reported that they have a good access to market due to the proximity of the Kabati slaughter house which is located within the Murang'a County. Pork sellers from Nairobi city and Thika town bought meat from the slaughter house creating demand. This does not concur with findings of studies done in western Kenya that found out that pig keepers were not in proximity to the market and normally middlemen bought their pigs and transported them to the slaughter houses in Nairobi and Thika (Eshitera et al., 2010; Kagira et al., 2010).

Majority of the respondents reported that they usually de-worm their pigs and almost all farmers reported to seek veterinary services for their herds. Thika sub-county veterinary officer reported that most farmers purchase oral piperazine which they administer either in water or feeds. These findings were not consistent with findings from a study that was done in western Kenya that found out that disease control measures such as spraying for external parasites, deworming and vaccination, were found to be rare (Mutua et al., 2011). Mutua et al. (2011) also observed disease was a lesser challenge in peri urban areas than rural areas which was not consistent to the findings of this study. This can be attributed to the shift in market demand for pork that has called for increased production and the improved production systems coupled with pig keepers increased awareness and provision of quality veterinary services to meet the market demand for quality pork

This study found several pig management practices to be significantly associated to porcine cysticercosis and these included; feeding (feeding pigs on swill from garbage, household leftovers and neighbours' leftovers) failure to de-worm pigs and purchasing of replacement pigs. Feeding of uncooked swill was also found to increase the odds of cysticercosis infection. Thika was unique in that while pig cysticercosis in many parts of Africa has been shown in many studies to be associated to absence of latrine and free range husbandly (Eshitera et al., 2010; FAO, 2012), all farmers in the area had latrines and free-range pig husbandly was none existent.

Feeding of swill had the strongest association to cysticercosis and was therefore the main risk factor of the disease in the study area. The farmers who fed their pig on swill mainly got it from the damp site where risk of contamination with human faeces and consequently Taenia solium eggs was high. Tin et al. (2015) also reported significant association of pig cysticercosis to feeding of swill where they observed that most housewives in Nay Pyi Taw Area collected swill which might have been contaminated with T. solium eggs from infected food preparers of swill collected houses. There was stronger association on occurrence of cysticercosis to feeding uncooked swill as compared to feeding swill in general. A study by Pondja et al. (2010) in Mozambique reported that cooking of swill kills tapeworm eggs reducing the risk of pig infection

Cysticercosis infection was also associated to failure to de-worm pigs. Cases of cysticercosis in Busia district of Kenya were found to be fewer by Eshitera et al. (2010) where de-worming was done regularly after every three months this concurs with the findings of this study since it found a significant association between the frequencies of deworming to the occurrence of pig cysticercosis. Studies have shown that low doses (5-10 mg/ kg/ day) of praziquantel have some activity against cysts and pigs can tolerate high doses of up to 50 to $70 \mathrm{mg} / \mathrm{kg} /$ day (Garcia et al., 2002) and therefore deworming may reduce transmission and prevalence of cysticercosis.

\section{Conclusion}

This study has reported the occurrence porcine cysticercosis in an area previously thought to have good husbandry practices that would not sustain transmission. The main risk to the occurrence and spreads of porcine cysticercosis in the study area was feeding pig on uncooked swill. Other factors that were found to have some bearing on porcine cysticercosis prevalence were feeding pig house hold left over, neighbour left over, and failure to de-worm pigs. The fact that most farmers sought veterinary services and de-wormed their pigs frequently indicates that an effective de-wormer may be used to control the parasite in the study area.

This study recommends that swill fed to pigs should be thoroughly cooked, farmers should be appraised on good pig husbandry practices to control and finally eradicate porcine cysticercosis and that the meat inspectors sensitized on the 
occurrence of the disease so as to be more vigilant during inspection to ensure only wholesome meat is passed for human consumption.

\section{Acknowledgements}

The researchers would like to appreciate County Government of Kiambu and Murang'a, Veterinary Services department for permission to carry out research and the farmers who participated in the study and allowed for data collection from their pig farms. The technical staff who assisted with data collection.

The research was funded through the Kenyatta University Vice Chancellor's 2015 Research Grant Fund and the financial support is acknowledged.

\section{References}

i. Ajala M.K., Adesehinwa A.O.K. and Mohammed, A.K. (2007). Characteristics of smallholder pig production in southern Kaduna State, Nigeria. American-Eurasian Journal of Agriculture and Environmental Sciences, 2(2): 182188

ii. Behnke R. and Muthami D. (2011). The contribution of livestock to the Kenyan economy. IGAD LPI Working Paper 03-11. Addis Ababa, Ethiopia: IGAD Livestock Policy Initiative.

iii. Boa, M. E., Bogh, H. O., Kassuku, A. A. and Nansen, P. (1995). The prevalence of Taenia solium metacestodes in pigs in northern Tanzania. Journal of Helminthology, 69: 113 - 117.

iv. Brooks P. H., Carpenter J.L., Barber J and Gill B.P. (1989). Production and welfare problems relating to the supply of water to growing finishing pigs. Pig Vet. J. 23:51-66.

v. 5.Carter N., Dewey C., Mutua F., de Lange C. and Grace D. (2013). Average daily gain of local pigs on rural and periurban smallholder farms in two districts of Western Kenya.

vi. Daniel W.W. (1999). Biostatistics: A Foundation for Analysis in the Health Sciences. 7th edition. New York: John Wiley \& Sons. WW Daniel1999Biostatistics: A Foundation for Analysis in the Health Sciences. 7th editionNew YorkJohn Wiley \& Sons pp. 134-160

vii. Eshitera E.E., Kitala P. M., Maingi N., Githigia, S. M. (2012). Prevalence of porcine cysticercosisand associated risk factors in free range pigs in Homa-Bay district, Kenya. University of Nairobi.

viii. FAO, (2012). Pig Sector Kenya. FAO Animal Production and Health Livestock, Country Reviews. No. 3. Rome.

ix. FAO, (2011). The State of Food and Agriculture 2010-2011. Women in agriculture. Closing the gender gap for development. Rome (available at http:/ / www.fao.org/ docrep/ 013/i2050e/i2050e00.htm)

x. Flisser, A. (2002). Epidemiological studies of taeniosis and cysticercosis in Latin America. In: Craig P, Pawlowski Z, editors. Cestode Zoonoses: Echinococcosis and Cysticercosis An Emergent and Global Problem. Amsterdam: IOS Press; pp. 3-12.

xi. Froese C., and Small D. (2001). Water consumption and waste production during different production stages in hog operations. St. Andrews, Manitoba: Manitoba Livestock Manure Management Initiative 42: 1627-1633.

xii. García, H. H., Carlton, A. W. E., Theodore, E. N., Osvaldo, M. T., Clinton, W., Jr., David, B., Vedantam, R., Victor, C. W. T., Peter, M. S., James, C. A., Ana, F., Dolores, C., Elsa, S., Jon, S. F., S. Manuel, M., Armando, E. G., Robert, H. G., Oscar, H. (2002) Current Consensus Guidelines for Treatment of Neuro cysticercosis Clinical Microbiology Review 15: $747-756$.

xiii. Haynes N.B. (2001). Keeping livestock healthy. 4th ed. Massachusetts: Storey publishing Pp?.

xiv. Ironkwe M. O. and Amefule K.U. (2008). Appraisal of indigenous pig production and management practices in Rivers state, Nigeria. Journal of Agriculture and Social Research (JASR), 8 (1) pp. 2-6

xv. Kagira J.M., Kanyari P.W.N., Maingi N., Githigia S.M., Ng'ang'a J.C. and Karuga J.W. (2010). Characteristics of the smallholder free-range pig production system in Western Kenya. Tropical Animal Health, 42: 865-873.

xvi. Kagira J.M., Kanyari P.W.N., Munyua W.K. and Waruiru R.M., (2003). The control of parasitic nematodes in commercial piggeries in Kenya as reflected by a questionnaire survey on management practices. Tropical Animal Health Production, 35: 79-84.

xvii. Kamuribo E.D., Chenyambuga S.W., Makene V.W., and Mathias S. (2011). Characteristics and production constraints of rural-based small-scale pig farming in Iringa region, Tanzania. Livestock Research for Rural Development, [online] http:/ / www.lrrd.org/ lrrd23/ 8/ Kari23172.htm

xviii. Kiambu County (2013). County integrated development plan 2013-2017.

xix. Kisakye, J. M. and Masaba, S. C. (2002). Cysticercus cellulosae in pigs slaughtered in and around Kampala City. Uganda J Agric Sci 7:23-4.

xx. KNBS, (2009). Kenya National Bureau of Statistics. Population and housing census highlights. http:/ / www.scribd.com/ doc/ 36672705/ Kenya-census-2009. (10th March 2011).

xxi. Lekule F.P. and Kyvsgaard N.C. (2003). Improving pig husbandry in tropical resource-poor communities and its potential to reduce risk of pig cysticercosis. ActaTropica, 87: 111- 117.

xxii. Mutua F. K., Dewey C., Arimi S., Ogara W., Levy M. and Schelling E. (2012). A description of local pig feeding systems in village smallholder farms of Western Kenya. Trop Anim Health Prod. 44(6):1157-62. doi: 10.1007/ s11250-011-0052-6. Epub.

xxiii. Mutua F. K., Dewey C. E., Arimi S. M., Ogora W. O., Githigia S. M., Levy M. and Schelling E. (2011). Indigenous pig management practices in rural villages of Western Kenya. Livestock Research for Rural Development, 23 (7).

xxiv. Mutua F., Arimi S., Ogara W., Dewey C. and Schelling E. (2010). Farmer perception on Indigenous pig farming in Kakamega District, western Kenya. Nordic Journal of African Studies, 19 (1): 43-57. 
xxv. Mutua F. K., Randolph T. F., Arimi, S. M., Kitala P. M., Githigia S. M., Willingham A. L., Njeruh F. M.(2007). Palpable lingual cysts, a possible indicator of pig cysticercosis, in Teso District, Western Kenya. J Swine Health Prod., 15(4): 206-212.

xxvi. Nantima N., Ocaido M. Davies J., Dione M., Okoth E. Mugisha A. and Bishop R. (2015). Characterization of smallholder pig production systems in four districts along the Uganda-Kenya border. Livestock Research for Rural Development, 27 (8): [online] http:/ / www.lrrd.org/lrrd27/ 8/ nant27166.htmlm

xxvii. NEMA. (2010). Kenya State of the Environment and Outlook 2010. Supporting the delivery of Vision 2030. National Environment Management Authority.

xxviii. Nguhiu PN., Kabuage LW and Mwangi SN. (2018). Prevalence of porcine cysticercosis by lingual examination insmall holder pig farms in Kiambu, Kenya. International Journal of Innovative Research and Development, 7(1): 356- 363

xxix. Ocampo L.M., Leterme P. and Buldgen A. (2005). A survey of pig production systems in the rain forest of the pacific coast of Colombia. Tropical Animal Health Production, 37: 315-326.

xxx. Peden D., Taddese G. and Mulugeta M. (2003). Improving the water productivity of livestock: An opportunity for poverty reduction: Ministry of Agriculture, Addis Ababa, Ethiopia.

xxxi. Petrus, N. P., Mpofu, I., Schneider, M. B. and Nepembe, M. (2011). The constraints and potentials of pig production among communal farmers in Etayi Constituency of Namibia. Livestock Research for Rural Development 23, (159). http:/ / www.lrrd.org/ lrrd23/ 7/ petr23159.htm

xxxii. Phengsavanh P., Ogle B., Stür, W., Frankow-Lindberg B.E. and Lindberg J.A. (2010). Feeding and performance of pigs in smaller-holder production systems in Northern Lao PDR. Tropical animal Health Production, 42: 16271633.

xxxiii. Pondja A., L. Neves L., MlangwaJ., Afonso S., FafetineJ., Willingham A. L., Thamsborg S. M. and Johansen M. V. (2012). Use of Oxfendazole to Control Porcine cysticercosisin a High Endemic Area of Mozambique. PLoS Neglected Tropical diseases, 6 (5).

xxxiv. Shields J. R. G., Mahan D. C. and GrahamP. L. (1983). Changes in swine body composition from birth to 145 kg. J. Anim. Sci., 57: 43- 54

xxxv. Sikasunge C. S., Phiri I. K. Phiri A. M., Dorny P., Siziya S., and Willingham A.L. (2006). Risk factors associated with porcine cysticercosisin selected districts of Eastern and Southern provinces of Zambia. Elsevier B.V. Veterinary Parasitology. Volume 143, Issue 1, 19 January 2007, Pages 59-66

xxxvi. Smith B. (2006). The Farming Handbook. Pietermaritzburg: CTA and University of KwaZulu-Natal Press, pp. 431

xxxvii. Thornton P. K. (2010). Livestock production: recent trends, future prospects. Phil. Trans. R. Soc., 365: 2853-2867.

xxxviii. Tin, A. K., Saw, B., Soe, S. W., Ye, H. and Lat, L. H. 2015. Epidemiological Survey on Porcine Cysticercosis in Nay Pyi Taw Area, Myanmar, Journal of Veterinary Medicine, vol. 2015, Article ID 340828, 5 pages,2015.doi:10.1155/ 2015/340828 https:// www.hindawi.com/journals/ jvm/ 2015/340828/

xxxix. Veary C.M. and Manoto S.N. (2008). Neurocysticercosis: a possible cause of epileptic form seizures in people residing in villages served by the Bethanie clinic in the North West Province of South Africa. Journal of the South African Veterinary Association, 79 (2): 84-88.

xl. Wabacha J.K., Maribei J.M., Mulei C.M., Kyule M.N., Zessin K.H. and Oluoch-Kosura W., (2004). Health and production measures for smallholder pig production in Kikuyu Division, central Kenya. Preventive Veterinary Medicine, 63: 197-210.

xli. Zoli, A., Shey-Njila, O., Assana, E., Nguekam, J. P., Dorny, P., Brandt, J. and Geerts, S. (2003). Regional status, epidemiology and impact of Taenia solium cysticercosis in Western and Central Africa. US National Library of Medicine 